\title{
A Simple Sinusoidal Buck Converter Working as A Single-Phase Grid-Connected Inverter
}

\author{
Hanny H. Tumbelaka ${ }^{1, a}$ \\ ${ }^{1}$ Electrical Engineering Department, Petra Christian University, Jalan Siwalankertao 121-131, Surabaya 60236, Indonesia \\ atumbehepetra.ac.id
}

\begin{abstract}
The need for a simple grid-connected inverter is increasing. The integration of a simple buck converter and a push-pull converter to be a grid-connected inverter is presented in this paper. The buck converter is controlled by a sinusoidal duty ratio to produce a series positive half-cycle of a sine wave. Then, the push-pull converter solves it to generate the complete sinusoidal output voltage and current. Moreover, grid synchronization works properly by sensing the grid voltage, which is then used as a reference voltage to connect the inverter to the grid successfully. The grid sees the inverter as a resistive load with a unity power factor. The total harmonic distortion (THD) of the grid current is $4.87 \%$ for the THD grid voltage of $2.07 \%$.
\end{abstract}

Keywords: buck converter, grid-connected inverter, sinusoidal duty-ratio, push-pull converter, grid synchronization.

\section{Introduction}

A DC-AC converter or an inverter converts a DC quantity to an AC quantity. An inverter operates as an interface between a DC source such as batteries or a renewable energy source such as wind, hydro, solar energy, and an AC grid or loads. Nowadays, there are many renewable energy sources that are connected to the grid. Therefore, they need a grid-connected inverter.

There are many kinds of a single-phase inverter, for either a stand-alone or a grid-connected system. The most common inverter, particularly a voltage source inverter (VSI) is a singlestage or multi-stage pulse-width-modulation (PWM) inverter [1]-[6]. It comprises four or six power-electronic switches configured as a bridge with a filter. PWM signals control the switches to produce a sinusoidal AC waveform.

There is a shoot-through problem in high frequency switching transition between each leg's upper and lower transistors in a bridge VSI, which is generally overcome by a dead time mechanism. To mitigate the problem, a dual-buck inverter, and a two-boost (buck-boost) inverter [1][7][8] as well as a twin-buck inverter [9] has been established.

For further development, this paper proposes a different configuration for a small single-phase grid-connected inverter. The inverter only utilizes a single buck converter. Basically, a step-down (buck) DC-DC converter is used to convert a high $\mathrm{DC}$ value to a low $\mathrm{DC}$ value with a certain duty ratio. Since the duty ratio can be varied, it is possible to create a sinusoidal inverter. Therefore, this proposed inverter is simple and easy to implement. The controller is simple as well, including connection to the grid.

\section{Circuit Configuration}

\subsection{The Buck Converter Operation}

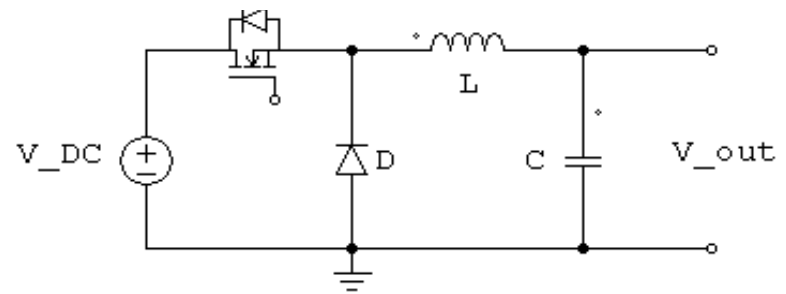

Figure 1. The Step-down (Buck) DC-DC converter.
A circuit diagram of a buck converter is described in Figure 1. The operating principle of the buck converter has been explained in [3][4]. The power electronic switches, which are a transistor and a diode, are turned on and off complementary. If $t_{\mathrm{ON}}$ is the length of time for the transistor is on, and $t_{\mathrm{OFF}}$ is the length of time for the transistor is off, then $\mathrm{t}_{\mathrm{ON}}+\mathrm{t}_{\mathrm{OFF}}=\mathrm{T}_{\mathrm{s}}$. The switching frequency $\left(\mathrm{f}_{\mathrm{S}}\right)=1 / \mathrm{T}_{\mathrm{S}}$. When the transistor is on, the inductor current $\left(i_{L}\right)$ ramps up. Energy is transferred from the DC source $\left(V_{D C}\right)$ to the inductor $(\mathrm{L})$, as well as to the capacitor (C) and the output. The voltage equation during this state is;

$$
V_{D C}=V_{o}+L \frac{d i_{L}}{d t}
$$

When the transistor is off, the energy stored in the inductor (L) is discharged to the capacitor and the output through the diode (D). The inductor current $\left(i_{L}\right)$ ramps down. The voltage equation during this state is

$$
0=V_{o}+L \frac{d i_{L}}{d t}
$$

In a stable operating cycle, the average inductor voltage is zero. Therefore,

$$
\left(V_{D C}-V_{O}\right) t_{O N}-V_{O} t_{O F F}=0
$$

where $t_{\mathrm{ON}}=\mathrm{KT}_{\mathrm{S}}$ and $\mathrm{t}_{\mathrm{OFF}}=(1-\mathrm{K}) \mathrm{T}_{\mathrm{S}} . \mathrm{V}_{0}$ is the output voltage.

Solving Equation (3), the relationship of the output-input voltage of the buck converter is

$$
\frac{V_{O}}{V_{D C}}=\frac{t_{O N}}{t_{O N}+t_{\text {OFF }}}=K
$$

$\mathrm{K}=$ duty ratio, in a range of $0-100 \%$. Equation (4) is valid when the inductor current stays in a continuous conduction mode $(\mathrm{CCM})$, which is $i_{L}(\mathrm{t})>0$.

\subsection{The Grid-Connected Inverter}

The output voltage of the buck converter is constant DC with ripples $\left(v_{0}(\mathrm{t}) \approx V_{0}\right)$ when $\mathrm{K}$ is constant. To build the inverter, the output voltage of the buck converter must be changed to be sinusoidal. To create a sinusoidal output voltage, $\mathrm{t}_{\mathrm{ON}}$ and $\mathrm{t}_{\mathrm{OFF}}$ must be varied in proportion to the amplitude of a sine wave. Thus, the duty ratio $(\mathrm{K})$ is not constant but must be controlled to be a sinusoidal pulse-width-modulation 
(SPWM). Since K is positive between $0-1$, then the duty ratio must be a function of $|\sin t|$. Equation (4) is modified to be;

$V_{o}=V_{D C} m_{a}|\sin t|$

where $m_{a}$ is the amplitude ratio, $0 \leq \mathrm{m}_{\mathrm{a}} \leq 100 \%$

Equation (5) shows that the converter only produces a positive voltage of a sine wave. To produce a whole sine-wave output voltage, every other positive cycle of the sine wave must be inverted to negative. This can be done by a push-pull converter [4].

The push-pull converter consists of two transistors and a single-phase three-winding transformer. The transistors and the transformer operate at a line frequency of $50 \mathrm{~Hz}$. The two transistors operate alternately. The first and second windings are attached to transistors. The third winding is connected to the grid. When the transistor S2 is on, the third winding produces a positive half-cycle of a sine wave. When the transistor S3 is on, the third winding produces a negative halfcycle of a sine wave by inverting the positive voltage of the sine wave. The three-winding transformer not only steps up the voltage value to the grid voltage but also assists in producing the negative cycle, as well as isolates the output from the input. Hence, the output voltage is a sinusoidal voltage for a full period $(20 \mathrm{~ms}$ for $50 \mathrm{~Hz})$.

Figure 2 shows the proposed sinusoidal buck converter working as a grid-connected inverter. The first block is the sinusoidal buck converter, and the second block is the pushpull converter connected to the grid. Moreover, a grid voltage sensor is installed at the grid to detect the grid voltage.

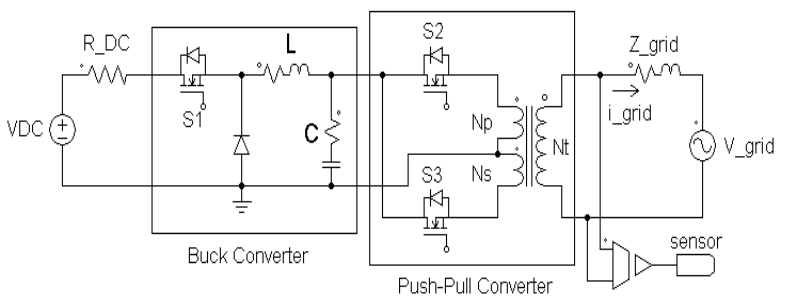

Figure 2. The Inverter circuit.

\section{The Inverter Controller}

There are two controllers, which are for the buck converter and for the push-pull converter. The circuit diagrams of the controller are shown in Figure 3 and 4.

\subsection{The Sinusoidal Buck Converter Controller}

To create a sinusoidal duty ratio, a simple SPWM controller is applied to the buck controller. This controller is slightly different from the literature [6], which is based on a current control VSI. Figure 3 shows that the output of the grid voltage sensor is used as the reference voltage $\left(V_{R E F}\right)$. The $V_{R E F}$ is modulated by two carrier signals of triangular waves with a fixed switching frequency of $5 \mathrm{kHz}$. The first triangular wave $\left(V_{T R I(1)}\right)$ is above the $t$-axis to produce SPWM signals for the positive half-cycle of the sine wave. The second triangular wave $\left(V_{T R I(2)}\right)$ is below the $t$-axis to produce SPWM signals for the negative half-cycle of the sine wave. Then, those two SPWM signals are merged to produce total SPWM signals to trigger the transistor S1. Hence, to build a sinusoidal inverter, Equation (5) is implemented by using the reference voltage, $V_{R E F}$. The switching action of the transistor $\mathrm{S} 1$ also produces a sine-wave inductor current. The inductor current ramps up and down following SPWM signals.
The waveform of the reference voltage is the same as the grid voltage. In case the grid voltage contains harmonics, the $V_{R E F}$ also has the same harmonics. As a result, the current flowing from the inverter to the grid has the same waveform as the grid voltage. Because the grid current and the grid voltage are in phase, then the power factor is equal to one [10].

\subsection{The Push-pull Converter Controller}

The $V_{R E F}$ is also controlled to create square wave signals with a frequency of $50 \mathrm{~Hz}$ for triggering transistors $\mathrm{S} 2$ and $\mathrm{S} 3$. The $V_{R E F}$ is compared with a zero voltage as seen in Figure 4. The result is a square wave with a constant duty ratio of $50 \%$. $t_{\mathrm{ON}}$ and $\mathrm{t}_{\mathrm{OFF}}$ are equal to a half-cycle of the sine wave. The triggering signal for the transistor $\mathrm{S} 2$ is inverse to the triggering signal for the transistor S3. When the signal for the transistor $\mathrm{S} 2$ is high, the signal for the transistor $\mathrm{S} 3$ is low and vice versa.

In Figure 3, there is a time delay (TD) block that shifts the $V_{R E F}$ by several degrees. As a result, there is a slight phase difference between the sine wave and the square wave to trigger transistors. The TD block has been explained in [8][9]. Without a phase shift, the inherent problem of zero-crossing distortion occurs. The cascade topology [8] solves the problem by feeding phase-shifted PWM to different cascade units. In twin-buck inverter [9], a phase difference between $V_{R E F}$ and square signals to trigger transistors is applied to mitigate the problem.

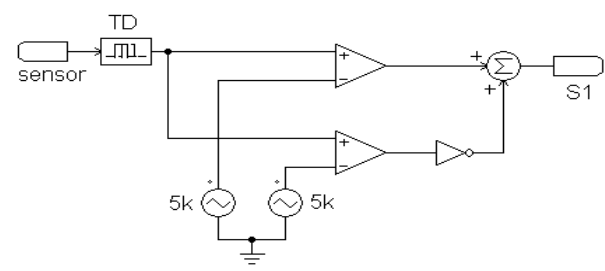

Figure 3. Buck converter controller.

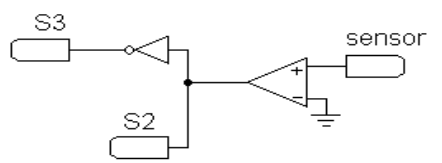

Figure 4. Push-pull converter controller.

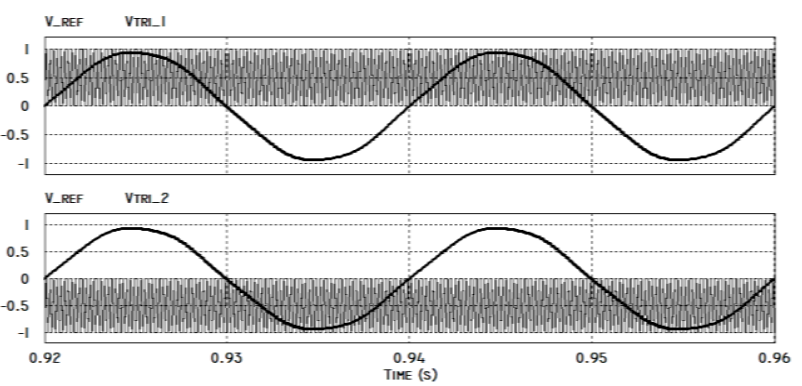

Figure 5. SPWM signal generation.

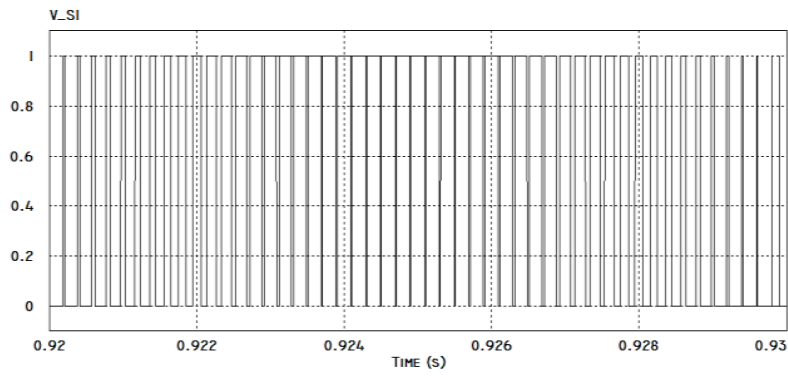

Figure 6. SPWM signal for triggering S1. 
Figure 5 demonstrates the reference signal $V_{R E F}$ and the carrier signals $V_{T R I(1)}$ and $V_{T R I(2)}$. In this case, the $V_{T R I}$ has an amplitude $=1$ and its frequency is $5 \mathrm{kHz}$. The amplitude ratio $\left(m_{a}\right)=0.98$. By using comparators, the controller generates SPWM signals for triggering transistor $\mathrm{S} 1$ as shown in Figure 6 . For the TD block, the phase delay is chosen to be $2.5^{\circ}$.

Figure 7 shows square wave signals for triggering transistors $\mathrm{S} 2$ and $\mathrm{S} 3$. The reference signal is compared with a zero voltage. During a positive half-cycle, $V_{R E F}>0$, the comparator output voltage S2 is high (1), and S3 is low (0). During a negative half-cycle, $V_{R E F}<0$, the comparator output voltage $\mathrm{S} 2$ is low (0), and S3 is high (1).

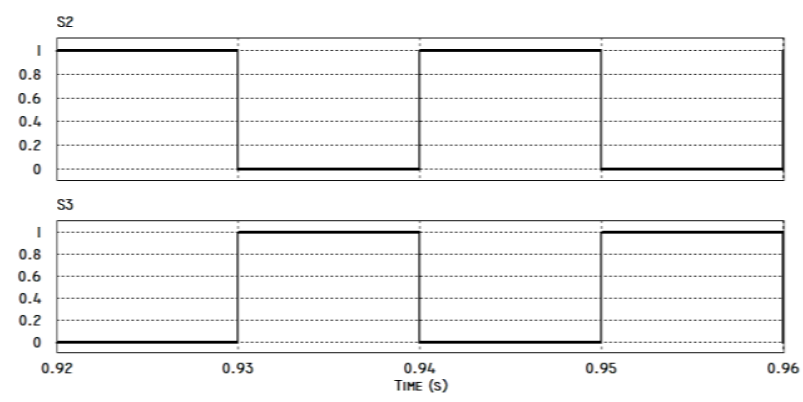

Figure 7. Square wave signals.

\subsection{Grid Synchronization}

For a grid-connected inverter, the output voltage of the inverter must be synchronized to the grid. The voltage, phase and frequency of the inverter and the grid must be the same.

To achieve those criteria, a grid voltage sensor is positioned at the grid terminal to sense the grid voltage. The grid voltage becomes the reference voltage $\left(V_{R E F}\right)$. When the $V_{R E F}$ is compared to zero voltage as mentioned in section 3.2 , then zero-crossing points of the grid-voltage wave and the invertervoltage wave are the same. As a result, the frequency and the phase of both voltages are the same.

The grid terminal voltage is around $220 \mathrm{~V}$. The inverter output voltage must also be the same around $220 \mathrm{~V}$. This can be achieved by setting the transformer ratio, the amplitude ratio of the SPWM signal $\left(m_{a}\right)$, and the gain of the grid voltage sensor.

\section{Results and Discussions}

The circuit in Figure 2 is examined using PSIM simulator to validate the concepts explained in previous sections. Circuit parameter values for simulation: $V_{D C}=36 \mathrm{~V}, R_{D C}=0.15 \Omega, L$ $=0.38 \mathrm{mH}, \mathrm{C}=47 \mu \mathrm{F}$, Transformer ratio: $\mathrm{Np}: \mathrm{Ns}: \mathrm{Nt}=1: 1$ : $9.85, \mathrm{~V}_{\text {grid }}=219.4 \mathrm{~V}, \mathrm{Z}_{\text {grid }}=1.115 \Omega$.

Figure 8 shows the grid voltage and the grid current. The grid voltage contains harmonics with a total harmonic distortion (THD) voltage of $2.07 \%$. The grid current waveform is identical to the grid voltage. The grid current also contains harmonics with THD current of $4.87 \%$. The grid current is in phase with the grid voltage as well. The power factor is 0.996 . It means that the grid sees the inverter as a resistive load. According to Ohm's Law, a resistor is a linear element that can make the current waveform equal to the supply voltage. The voltage and the current are in phase. For resistive loads, the active power is equal to the apparent power. Figure 9 shows the power supplied to the grid. This power waveform is identical to the typical waveform for a single-phase resistive load. This is the benefit of the proposed grid-connected inverter.
Figure 8 proves that the concept of the proposed gridconnected inverter is right. The inverter controller works satisfactorily. The sinusoidal buck converter controller successfully shapes the inverter output voltage and current to be similar to the reference voltage, which is basically the grid voltage. The process to generate $\mathrm{AC}$ sinusoidal voltage and current is represented by the capacitor/output voltage $V_{0}$ and the inductor current $i_{L}$ (Figure 10). The inductor current ramps up (down) when the transistor is switched on (off). Because the duty ratio is a function of the $V_{R E F}$, then the inductor current looks like the $V_{R E F}$ waveform with ripples according to Equations (1) and (2). Figure 10 also shows the buck converter output voltage with small ripples due to the capacitor. Hence, the buck converter successfully produces the sinusoidal voltage and current. They look like a waveform of the fullwave rectifier.

The inductor current $i_{L}$ is divided into the capacitor current and into the push-pull circuit current. The inductor current ripples flow to the capacitor. In a steady state, the average capacitor current is zero. The average inductor current goes to the two transistors in the push-pull circuit as described in Figure 11 .

Figure 11 explains the operation of the push-pull converter controller. In this circuit, the current is split into the currents of transistors $\mathrm{S} 2\left(i_{S 2}\right)$ and $\mathrm{S} 3\left(i_{S 3}\right)$. The current is flowing when the transistor conducts. The on and off states of the transistor is controlled by the signals shown in Figure 7. Thus, the synchronization process is successful. Moreover, $i_{S 3}$ will be inverted by the three-winding transformer to negative. As a result, the inverter will deliver a continuous sinusoidal current to the grid as shown in Figure 8.

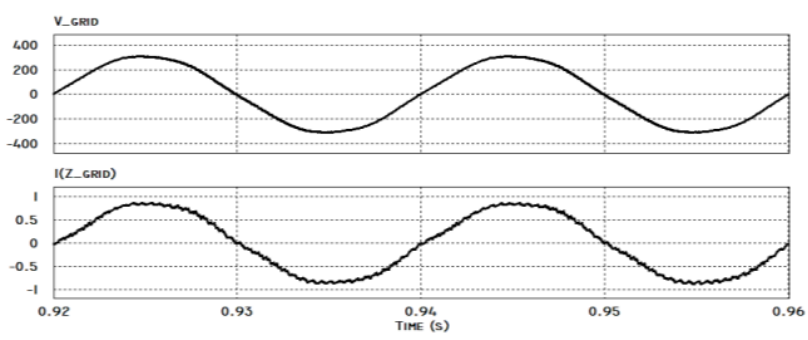

Figure 8. Grid voltage (top) and current (bottom).

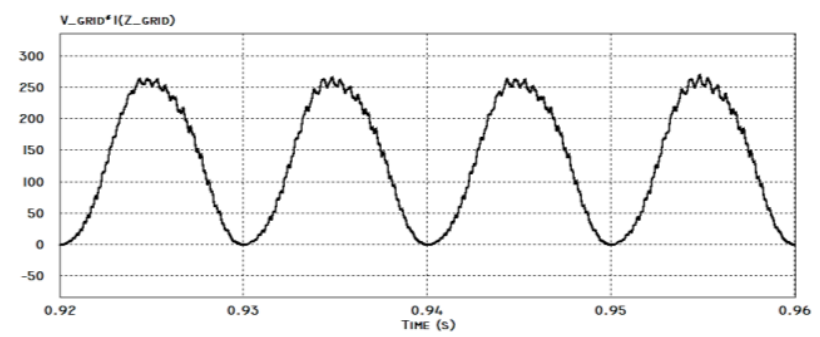

Figure 9. Grid power.

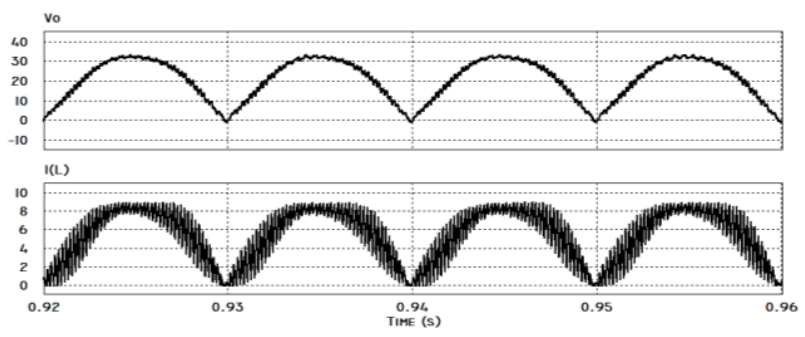

Figure 10. Capacitor/output voltage $V_{0}$ (top) and inductor current $i_{L}$ (bottom) 


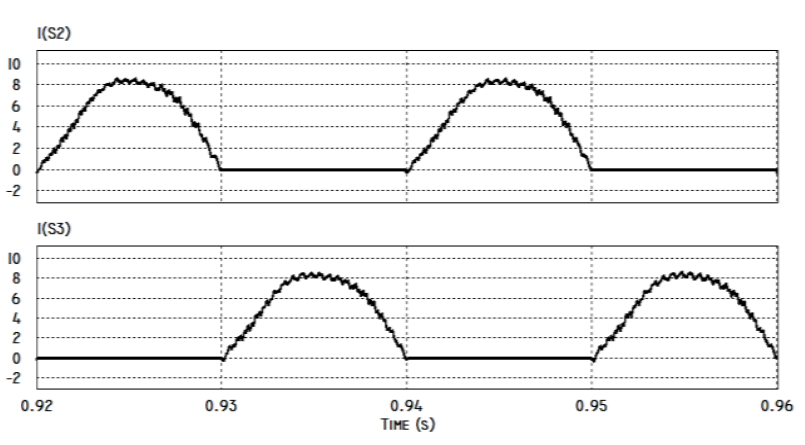

Figure 11. Push-pull circuit currents.

The power delivered to the grid in Figure 9 is affected by Equation (6) as follows [11],

$P_{R}=\frac{V_{S} V_{R}}{Z} \sin \delta$

where:

$V_{S}=$ sending-end voltage

$V_{R}=$ receiving-end voltage

$Z=$ impedance between buses

$\delta=$ angle between bus voltages

Equation (6) explains that the power flow is affected by the grid $\left(V_{R}\right)$ and the inverter voltage $\left(V_{S}\right)$ and the impedance $(Z)$ between them. The inverter voltage is predominantly $V_{D C}$.

From the circuit in Figure 2, the parameters at the lowvoltage side of the three-winding transformer significantly affect the power flow. This can be observed if all voltages dan impedances are transferred and concentrated on either lowvoltage side or high-voltage side. Obviously, the change of DC source voltage and resistance is more crucial than the grid voltage and impedance.

Table 1. Influence of $\mathrm{R}_{\mathrm{DC}}$ in power flow

\begin{tabular}{ccc}
\hline $\mathrm{R}_{\mathrm{DC}}$ & Power $(\mathrm{W})$ & Grid Current $(\mathrm{A})$ \\
\hline $0.12 \Omega$ & 142.2 & 0.653 \\
$0.15 \Omega$ & 134.1 & 0.613 \\
$0.18 \Omega$ & 124.9 & 0.571 \\
\hline
\end{tabular}

Table 2. Influence of $\mathrm{V}_{\mathrm{DC}}$ in power flow

\begin{tabular}{ccc}
\hline $\mathrm{V}_{\mathrm{DC}}$ & Power $(\mathrm{W})$ & Grid Current $(\mathrm{A})$ \\
\hline $35 \mathrm{~V}$ & 93.2 & 0.426 \\
$36 \mathrm{~V}$ & 134.1 & 0.613 \\
$37 \mathrm{~V}$ & 176.1 & 0.826 \\
\hline
\end{tabular}

Table 1 shows the changes in power and current when $\mathrm{R}_{\mathrm{DC}}$ is varied. $V_{D C}$ is kept constant at $36 \mathrm{~V}$. The higher the $\mathrm{R}_{\mathrm{DC}}$, the lower the power and the current to the grid. Moreover, Table 2 shows the variations in power and current when $\mathrm{V}_{\mathrm{DC}}$ is altered. $\mathrm{R}_{\mathrm{DC}}$ is kept constant at $0.15 \Omega$. On the contrary, the higher the $\mathrm{V}_{\mathrm{DC}}$, the higher the power and the current to the grid. These facts agree with Equation (6).

\section{Conclusion}

This paper proposes the implementation of a simple and small sinusoidal buck converter as a grid-connected inverter. The inverter interfaces a DC source to an AC grid. A buck converter with a sinusoidal duty ratio is applied to create a series positive half-cycle of a sine wave. Then, the push-pull converter inverts every other positive cycle of the sine wave to negative, so that the inverter successfully produces the complete sinusoidal output voltage and current. Moreover, the grid synchronization by sensing the grid voltage works properly so that the inverter can be connected to the grid successfully. The grid sees the inverter as a resistive load with a unity power factor.

\section{References}

[1]. Y. Xue, L. Chang, S. B. Kjær, J. Bordonau, and T. Shimizu. Topologies of Single-Phase Inverters for Small Distributed Power Generators: An Overview, IEEE Trans. Power Electronics, vol. 19, no. 5, pp. 1305-1314, Sep. 2004.

[2]. S. Kjaer, J. K. Pedersen, and F. Blaabjerg. A Review of Single-Phase Grid Connected Inverters for Photovoltaic Modules, IEEE Trans. Industry Applications, vol. 41, no. 5, Sep./Oct. 2005, pp. 1292-1306.

[3]. M. H. Rashid et al., Power Electronics: Circuits, Devices and Applications. $4^{\text {th }}$ edition, Pearson Education Limited, 2014

[4]. N. Mohan, et al. Power Electronics: Converters, Applications, and Design. $3^{\text {rd }}$ edition. John Wiley \& Sons, 2002

[5]. Shiqi Kan, et.al. Second Harmonic Current Reduction in Front-End DC-DC Converter for Two-Stage SinglePhase Photovoltaic Grid-Connected Inverter, IEEE Transactions on Power Electronics, vol. 34, no. 7, July 2019, pp. 6399-6410.

[6]. Noor Syafawati Ahmad et.al. Single-Phase GridConnected Inverters with Simplified SPWM Control, IEEE Open Journal of Power Electronics, vol. 1, 2020, pp. 170-179.

[7]. Zhilei Yao, Lan Xiao, and Yangguang Yan, H.L. DualBuck Full-Bridge Inverter with Hysteresis Current Control, IEEE Transactions on Industrial Electronics, vol. 56, no. 8, 2009, pp. 3153-3160.

[8]. Pengwei Sun, et.al. Cascade Dual Buck Inverter with Phase-shift Control, IEEE Transaction on Power Electronics, vol. 27, no. 4, April 2012, pp. 2067-2012.

[9]. Hanny H. Tumbelaka. A Single-Phase Twin-Buck Inverter, Lecture Notes in Electrical Engineering vol. 365, 2016, pp. 193-202.

[10]. Nunez-Zuniga, T.E. and J.A. Pomilio. Shunt Active Power Filter Synthesizing Resistive Loads, IEEE Trans. on Power Electronics, 17(2). 2002, pp. 273-278.

[11]. B. L Theraja and A. K Theraja, A Textbook of Electrical Technology, Chapter 37, S. Chand \& Company Ltd, 2005. 